\title{
Implementation and results of a gastrointestinal cancer screening program in an Amazon rainforest village: A descriptive study
}

\section{(ㄷ)(i)}

Authors

Pedro Averbach ${ }^{1}$, Angelo Paulo Ferrari², Cristiana M Toscano ${ }^{3}$, José Luiz Borges ${ }^{4}$, Marcelo Averbach ${ }^{4}$

Institutions

1 Hospital das Clínicas da Faculdade de Medicina da Universidade de São Paulo, Brazil

2 Escola Paulista de Medicina da Universidade Federal de São Paulo, Brazil

3 Departamento de Saúde Coletiva, Instituto de Patologia Tropical e Saúde Pública, Universidade Federal de Goiás, Brazil

4 Instituto Sírio-Libanês de Ensino e Pesquisa, São Paulo, Brazil

submitted 5.6 .2020

accepted after revision 4.1.2021

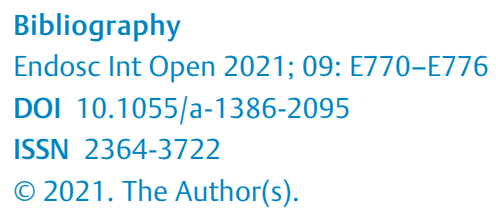

\section{Introduction}

Delivering health care services to remote populations is a challenge to public health systems worldwide. Data from Australia show that people living in remote and rural areas tend to have

\section{ABSTRACT}

Background and study aims Gastrointestinal cancer is an important cause of death worldwide. Remote populations are especially vulnerable to these conditions due to reduced access to screening and adequate treatment. In this context, the Belterra project was designed as a pilot taskforce to deliver gastrointestinal screening to an underserved Amazonian population and to spread knowledge and practice to local health workers. This study aimed to describe the implementation and present the results of the Belterra Project.

Patients and methods The project took place between October 2014 and December 2017 in Belterra, Pará, Brazil. Public-private partnerships were obtained and were essential for funding. The project required complex logistic solutions to provide gastrointestinal screening to every inhabitant between 50 and 70 years of age, including medical equipment and personal transportation to a remote area. Subjects were asked about their medical history, and received a physical examination, endoscopic examinations, and stool tests.

Results Over the course of 19 expeditions, we screened 2,022 inhabitants of Belterra, aged 50 to 70 years. Five colorectal and six gastric adenocarcinomas were diagnosed, as were several lower-stage lesions. Overall, $26 \%$ of the participants undergoing colonoscopy showed some type of colonic lesion.

Conclusions Notwithstanding the geographical, cultural, and financial barriers, this study suggests that the implementation of a gastrointestinal cancer screening program for remote Brazilian populations is feasible, reaching high adherence. Although logistics is very demanding, such campaigns may be a good strategy to provide mass gastrointestinal cancer screening for underserved populations. 
many countries [2-7]. Cancer outcomes are worse for rural patients, and more advanced cancer stages at diagnosis may explain this difference [8]. It is difficult to measure the impact of remoteness itself, as there are other health determinants underpinning this scenario such as lower socioeconomic status and medical data underreporting in these locations.

In an attempt to overcome this issue, the Belterra Project (BP) was set up as a pilot initiative for gastrointestinal cancer screening in an Amazon rainforest village. It addressed population awareness of colorectal cancer screening, healthcare assistance, and medical capacity expansion for gastrointestinal cancer screening.

The objective of this study was to describe the implementation and present the results of the BP, which was created to provide gastrointestinal cancer screening for a small population in the Amazon rainforest.

\section{Patients and methods}

\section{Study design and ethical concerns}

This descriptive study was conducted at the Hospital Sírio-Libanês. The description of the BP was approved by the Local Research Ethical Committee (register number 1.273.137) on October 9, 2015.

\section{Setting}

Belterra is a small town in the Amazon rainforest, on the banks of the Tapajos River. It was founded in 1934 by Henry Ford as a center for the extraction and sale of latex for the American automobile industry. The municipality area is $2,640.699 \mathrm{~km}^{2}$, with over $80 \%$ of forest preservation area. Its population was estimated at 18,000 inhabitants in 2014, most of whom lived in rural areas. Of this, the subpopulation aged 50 to 70 years has been estimated at 2,359 people. The main economic activities include subsistence agriculture and fishing. The town's health infrastructure is poor, consisting of only six small health units with five nurses and 40 community health agents. There is only one hospital where six doctors work, and there are no endoscopic or surgical units. The nearest secondary health facility is located $34 \mathrm{~km}$ from Belterra.

\section{Data collection}

Data were collected using standard forms filled out by doctors and medical students enrolled in the program. Data included general and demographic information on each patient, endoscopic exam results, and anatomopathological results. All data were then entered into the REDCap (Research Electronic Data Capture) platform [9] and available to researchers only. Only clinical information specifically concerning an individual participant was sent to local health providers.

\section{BP description and implementation}

As previously stated, the BP encompasses three key goals: address population awareness of colorectal cancer screening, medical capacity expansion, and healthcare assistance. The first step was to raise awareness of the importance of screening for gastrointestinal cancer among the population and health- care agents. To this end, marketing material was developed, and was strategically placed in different regional locations and delivered to the residents.

The second step was to increase the theoretical knowledge and improve the technical skills of local health professionals. Medical students, residents, and endoscopists from neighboring cities were invited to participate in training under the supervision of experienced endoscopists.

The third step consisted of offering gastrointestinal cancer screening to every individual between 50 and 70 years of age based on their medical history (risk factor, lifestyle, social determinants), physical examination, endoscopic examinations (including Helicobacter pylori testing), and stool tests. From October 2014 to December 2017, 19 expeditions to Belterra took place. Each expedition lasted four days, during which endoscopies (EGD) and colonoscopies were performed, and fecal samples were analyzed within 1 week from collection for fecal occult blood, using a Biopix qualitative fecal immunochemical test (FIT) and parasitological tests. Whenever a lesion was diagnosed, an endoscopic treatment with polypectomy or endoscopic mucosal resection was attempted if possible. In case of advanced lesion biopsies were taken and sent to histopathological exam. Bowel preparation regimen was constituted of clear liquid diet on the day before the exam and 500 milliliters of $20 \%$ mannitol solution orally 6 hours previous to the expected time of the exam. A standard video endoscope (EG530 WR, Fujifilm Corporation, Tokyo, Japan) was used for upper gastrointestinal endoscopies (EGD) and adult video colonoscope (EC $530 \mathrm{WL}$, Fujifilm Corporation, Tokyo, Japan) for colonoscopy using an imaging processor FUJIFILM - EPX 2500.

In every expedition, three experienced endoscopists, one endoscopy resident, two medical students, two nurses, one nurse technician, and four or five other support members from different regions of the country comprised the team responsible for delivering screening to the target population.

Community health care agents were responsible for explaining the procedures, providing drugs for bowel preparation, and providing general information to the population. Any patient with conditions discovered during the examinations that could not be managed endoscopically was referred to a secondary hospital located in Santarem city, 34 km away from Belterra.

\section{Barriers and facilitators for implementation.}

Public-private partnerships were established in order to secure not only financial funding, but also to guarantee adequate treatment to patients whose lesions could not be managed endoscopically, to collect and analyze data, and to provide medical material and expertise.

Due to the demographic characteristics of the region, the project utilized not only the local hospital but also a boat ( $\triangleright$ Fig. 1), where two endoscopy units were built ( $\triangleright$ Fig. 2) in order to deliver screening to the riverside and hard-to-reach populations. Both facilities had very limited resources, and therefore all medical materials including image processors, screens, gastroscopes and colonoscopes, anesthetics, syringes, needles, sharps disposals, endoscopic tweezers, electrosurgery equipment, oxygen tanks, emergency carts, endoscopes cleaning 


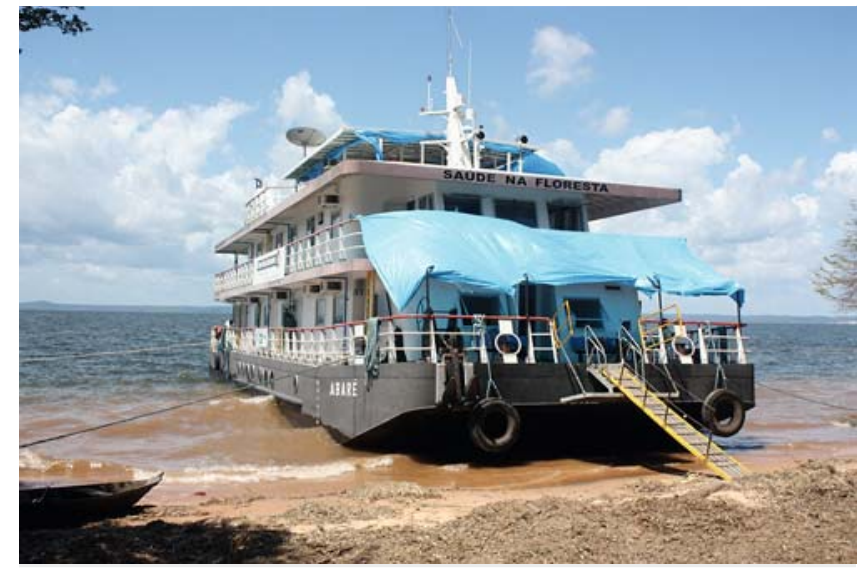

- Fig. 1 The Abaré boat, a floating hospital where two endoscopy units were built to increase access to gastrointestinal screening among remote riverside populations.

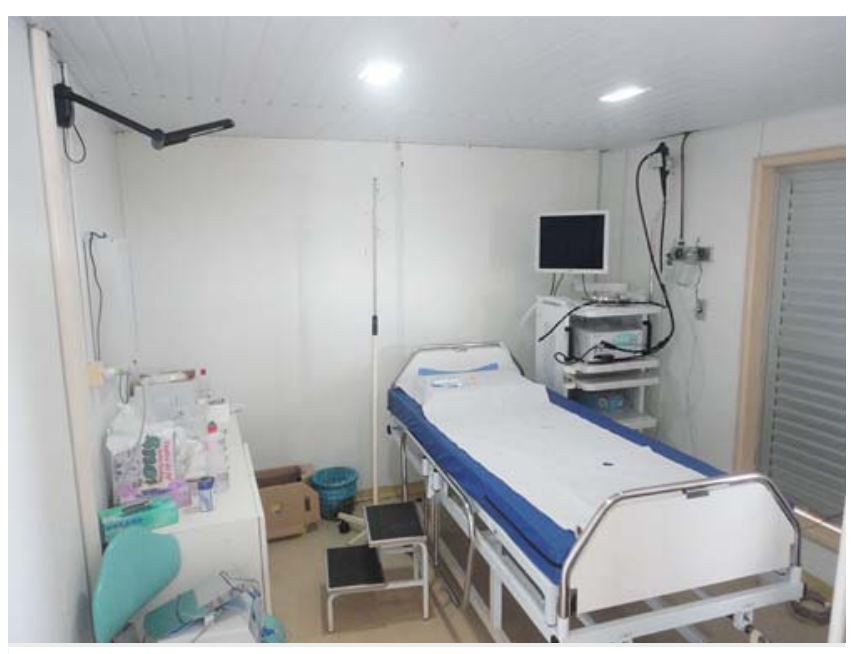

- Fig. 2 View of the inside of an endoscopy unit in Abaré.

Municipal de Belterra to receive adequate treatment and follow-up. $>$ Fig. 3 is a flowchart of the algorithm use for this project.

\section{Results}

\section{Screening results}

During the 19 expeditions to Belterra, 2,022 individuals were enrolled in the program and a mean of 80.9 patients were screened per campaign. The characteristics of the participants are shown on $>$ Table $\mathbf{1}$. Among the 1,903 participants whose tients. Patients diagnosed with adenomatous polyps and those with positive $H$. pylori tests were then referred to the Hospital pital was located 45 kilometers away from Belterra. Patients with adenocarcinoma were referred to this hospital which was then held responsible for staging and treatment of these pawith positive H. pylori tests were then referred to the Hospital

products, and other basic items needed for the procedures

Further, the BP relied on backup support from the Hospital Regional do Baixo Amazonas, which was the local secondary hospital that received referred patients who needed further treatment in the event of unexpected complications. This hos(2)

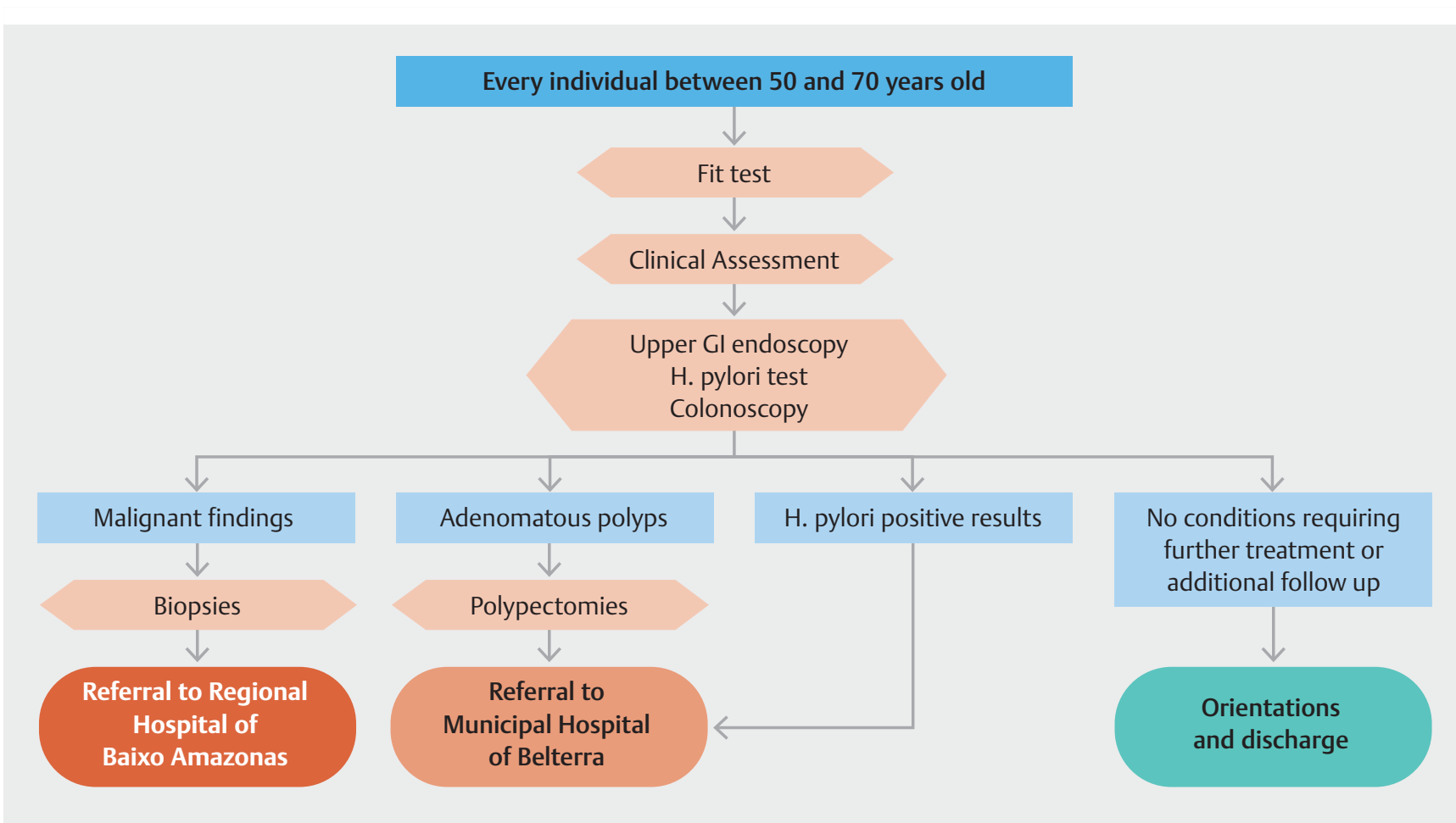

Fig. 3 Flowchart of the algorithm. 
- Table 1 Demographic characteristics and risk factors in the studied population.

\begin{tabular}{|c|c|c|c|}
\hline \multicolumn{2}{|l|}{ Characteristic } & \multirow{2}{*}{$\begin{array}{l}\text { Number } \\
974\end{array}$} & \multirow{2}{*}{$\begin{array}{l}\text { Percentage } \\
48.2\end{array}$} \\
\hline Gender & Male & & \\
\hline & Female & 1048 & 51.8 \\
\hline \multirow[t]{2}{*}{ Age } & $<60$ & 1260 & 62.3 \\
\hline & $\geq 60$ & 762 & 37.7 \\
\hline \multirow[t]{2}{*}{ Body mass index } & $<27.5$ & 1107 & 57.3 \\
\hline & $\geq 27.5$ & 824 & 42.7 \\
\hline \multirow{2}{*}{$\begin{array}{l}\text { Previous colonos- } \\
\text { copy }\end{array}$} & Yes & 160 & 8.1 \\
\hline & No & 1816 & 91.9 \\
\hline \multirow{4}{*}{$\begin{array}{l}\text { Alcohol consump- } \\
\text { tion }\end{array}$} & No & 1353 & 69.0 \\
\hline & <once a month & 306 & 15.6 \\
\hline & <once a week & 210 & 10.7 \\
\hline & >once a week & 91 & 4.7 \\
\hline \multirow{2}{*}{$\begin{array}{l}\text { Smoking history } \\
\text { (> } 100 \text { cigarettes } \\
\text { in lifetime) }\end{array}$} & Yes & 973 & 50.5 \\
\hline & No & 955 & 49.5 \\
\hline
\end{tabular}

fecal occult blood test (FOBT) was available, 64 patients (3.4\%) had a positive result. Of these 64 positive results, one patient (1.6\%) was diagnosed with colorectal adenocarcinoma and 13 had at least one polyp diagnosed and removed. A total of 31 polyps were removed from these patients as a few had more than one polyp removed. Low-grade dysplasia was diagnosed in nine patients, another two patients had adenomas with high-grade dysplasia, and two had synchronic polyps with lowand high-grade dysplasia. From the remaining patients with negative FOBT, $38.2 \%$ had at least one abnormal finding, with polyps accounting for $65.4 \%$ of the cases. From the 459 patients with negative FOBT, but with polyps diagnosed on colonoscopy, 41 had high-risk adenomas and four had adenocarcinomas. Other abnormal findings were diverticulum (50.4\%), flat lesion (3.8\%), colitis (3.3\%) and arterial-venous malformation (1.6\%). Regarding the upper endoscopy findings within patients with negative FOBT, four patients had gastric cancer diagnosed and one had duodenal cancer. Other abnormal find- ings were esophagitis (7.7\%) and gastric (26.7\%) and duodenal (25.6\%) peptic ulcers.

Overall, 1,952 (96.5\%) participants underwent colonoscopy, the remaining patients either did not show up on the scheduled day $(n=64)$ or did not have adequate bowel preparation $(n=8)$. The colonoscopy was considered complete in $98.1 \%$ when the scope reached the cecum. The main reasons for an incomplete exam were bad quality of bowel preparation $(n=31)$ and anatomical difficulties $(n=6)$. This study had 514 patients with colonoscopic findings. Of the 471 polyps found, the majority were adenomas and were subdivided into high-risk (defined as a lesion with any of the following characteristics: size larger than $10 \mathrm{~mm}$, more than $50 \%$ of villous component or high-grade dysplasia) and low-risk adenomas. High-risk adenomas represented $14.0 \%$ of the total number of adenomas. the adenoma detection rate (ADR) was $16.5 \%$. The main findings from this test are summarized in $>$ Table 2 .

Colorectal polyps were diagnosed in 472 patients. The majority of the patients presented with adenomas $(n=284)$, of which 267 (92.4\%) had tubular adenomas, while 22 had tubulovillous adenomas (7.6\%). Regarding the histologic grade, $276(95.5 \%)$ had a total of 370 low-grade dysplasia, while 13 (4.5\%) had high-grade dysplasia. Another 27 patients had sessile serrated lesions (SSL), of which two had high-grade dysplasia and 20 had low-grade dysplasia. Data were not available for five patients with SSL. The distribution of the polyps was 637 (57.5\%) located in the right colon (cecum, ascending and transverse colon) and $440(40.1 \%)$ in the left colon (descending coIon, sigmoid, and rectum). There were 21 polyps with unknown localization. The characteristics and location of the colorectal polyps are shown in $>$ Table 3 . The average size of polyps removed was $5 \mathrm{~mm}$ (range 1 to $40 \mathrm{~mm}$; median $4 \mathrm{~mm}$ ).

Among the five patients diagnosed with colorectal adenocarcinoma, one had a positive FOBT result. Moreover, of 45 patients with high-risk adenoma, 41 tested negative for fecal occult blood.

Overall, 1,958 participants underwent upper endoscopy (96.83\%) and the remainder did not show up on the scheduled day (64 patients). The main findings are detailed in $>$ Table 4.

No adverse events requiring medical intervention were observed during the program.

- Table2 Main colonoscopic and histopathological findings $(n=1,952)$.

\begin{tabular}{|l|l|l|r|}
\hline Colonoscopic findings & Number (\%) & Histopathological finding & Number (\%) \\
\hline Polyps & $471(24.12)$ & Low-risk adenoma & $277(14.20)$ \\
\cline { 2 - 4 } & & High-risk adenoma & $45(2.31)$ \\
\cline { 2 - 4 } & & Hyperplastic polyp & $149(7.63)$ \\
\hline Tumors & $7(0.61)$ & Adenocarcinoma & $5(0.26)$ \\
\hline & & Neuroendocrine tumor & $2(0.10)$ \\
\hline Flat lesions & $31(1.59)$ & Low-risk adenoma & $31(1.59)$ \\
\hline
\end{tabular}


- Table 3 Polyps characteristics and location.

\begin{tabular}{|l|l|l|l|l|}
\hline Characteristic or location & Number of patients & $\begin{array}{l}\text { Percentage of patients } \\
\text { with polyps (\%) }\end{array}$ & Number of polyps & Percentage of polyps (\%) \\
\hline Sessile & 429 & 86.3 & 672 & 84.3 \\
\hline Pedunculated & 57 & 11.5 & 113 & 14.2 \\
\hline No data available & 10 & 2.1 & 11 & 1.4 \\
\hline Transverse colon & 137 & 23.1 & 271 & 24.7 \\
\hline Sigmoid & 130 & 22.0 & 216 & 19.7 \\
\hline Ascending colon & 128 & 21.6 & 259 & 23.6 \\
\hline Descending colon & 77 & 13.0 & 136 & 12.4 \\
\hline Cecum & 52 & 8.8 & 107 & 9.2 \\
\hline Rectum & 52 & 8.8 & 88 & 8.0 \\
\hline No data available & 16 & 2.7 & 21 & 1.9 \\
\hline
\end{tabular}

- Table 4 Main upper endoscopic and histopathological findings $(\mathrm{n}=1,958)$.

\begin{tabular}{|l|l|l|l|}
\hline $\begin{array}{l}\text { Endoscopic } \\
\text { findings }\end{array}$ & $\begin{array}{l}\text { Number } \\
(\%)\end{array}$ & $\begin{array}{l}\text { Histopathological } \\
\text { finding }\end{array}$ & $\begin{array}{l}\text { Number } \\
\mathbf{( \% )}\end{array}$ \\
\hline $\begin{array}{l}\text { Suspected } \\
\text { gastroduo- } \\
\text { denal } \\
\text { lesions }\end{array}$ & $9(0.46)$ & Adenocarcinoma & $6(0.31)$ \\
\cline { 2 - 4 } & & Lymphoma & $1(0.05)$ \\
\hline & & Neuroendocrine tumor & $1(0.05)$ \\
\hline & & $\begin{array}{l}\text { High-grade dysplasia } \\
\text { adenoma }\end{array}$ & $1(0.05)$ \\
\hline
\end{tabular}

\section{Discussion}

To the best of our knowledge, this is the first report of a colorectal cancer screening program within an Amazonian population and the findings are key to future interventions in this region.

Providing gastrointestinal screening to remote and underserved populations has proved to be a challenge. Notwithstanding the geographical, cultural, and financial barriers, we suggest that through the participation of volunteers and the establishment of partnerships with the public and private sector, the implementation of a cancer screening program for remote Brazilian populations is feasible. Of the several barriers that have been identified, we highlighted difficulties in transporting all medical material and professionals to an unequipped hospital, which was required to reach riverside populations that are not accessible by roads. We also highlighted difficulties in providing adequate training to health professionals who are not familiar with population-based screening.

In addition, we presented main results from the project, which included diagnosis of lesions in $26 \%$ of participants undergoing colonoscopy, and nine patients diagnosed with malignancies undergoing upper gastrointestinal endoscopy.
We observed over $95 \%$ adherence to the screening project, which is considered very high. Other studies from different countries have shown much lower adherence rates, such as $10.5 \%$ and $45.4 \%$ [10-12]. This surprisingly high adherence is likely due to a conjunction of factor, such as the investment in marketing and promotion of the screening program through outdoor posters, flyers, and the work of community health care agents who promoted the campaign for population awareness. Further, the implementation of such a program in a small and restricted population facilitates the spread of the information among all inhabitants.

Moreover, in this study, the ADR was $16.5 \%$, below that recommended by the American Society for Gastrointestinal Endoscopy, which considers the target ADR of $20 \%$ to be a quality indicator [13]. The low ADR observed in this study may be explained by the characteristics of the population screened within this study, or by the lack of imaging magnification modes or high-resolution endoscopic devices used, which may have compromised our ability to diagnose small lesions [1418].

Five patients $(0.26 \%)$ were diagnosed with colorectal adenocarcinoma. The adenocarcinoma detection rate varies widely in the literature, from $0.2 \%$ to $3.1 \%$ [19-22]. Therefore, our results fall within the variability described in other studies.

Unlike many colorectal screening projects [11-12,23-28], this study provided every participant with both FOBT and colonoscopy, making it possible to analyze the efficacy of these examinations under the circumstances of remote populations. The positivity of FOBTs observed in this study was similar to that in other studies, with a positivity rate of $2.4 \%$ to $7.7 \%$ [25-28]. We found a surprisingly low sensitivity of FIT for adenocarcinoma in our study, among the five patients diagnosed with adenocarcinoma, only one (20\%) had a positive FOBT. Other studies that have also performed colonoscopy and FOBTs in all patients have found positive FOBT results in patients diagnosed with colorectal adenocarcinoma at higher rates than those observed in this study $[19,20]$. The low sensitivity of the 
FOBT in this study raises concerns about its use in remote regions, where the storage and transportation of stool samples is not optimal and may lead to decreased efficacy.

There are controversies regarding gastric cancer screening efficacy, and recommendations are based on its incidence in each country or region. Countries with high gastric cancer incidence, such as Japan, South Korea, Venezuela, and Chile, have implemented screening, each of them with their own protocol regarding time interval and modality of screening [29-31].

Nevertheless, our project had a series of limitations that must be pointed out. First, given the voluntary nature of this work and the multiple sources of funding, an accurate measurement of the actual costs is underestimated and out of the scope of this paper. However, this factor plays a major role when considering the possibility of reproducing this model on a nationwide scale. Further, data are lacking regarding colon preparation and scope withdrawal time, which are considered important aspects when analyzing the colonoscopy quality. Finally, we did not follow up the patients with adenomatous polyps and invasive carcinomas; therefore, we lack information about their clinical stages and further treatments.

Clinical studies comparing the benefits and risks of these interventions and further cost-effectiveness analyses addressing this topic are needed. Another remaining question concerns the feasibility of adapting this model for larger populations, within the context of national public health systems.

\section{Conclusions}

Despite the geographical, cultural, and financial barriers, this study suggests that through volunteer participation and the establishment of partnerships with the public and private sector, the implementation of a gastrointestinal cancer screening program for remote Brazilian populations is feasible. Our results showed that nearly $26 \%$ of Belterra inhabitants who underwent colonoscopy screening had some type of colonic lesion.

\section{Acknowledgements}

The authors thank the doctors, medical students, and nurses who participated in the project and made it possible. They also thank Eduardo Fernandes Abrantes for helping with the input and extraction of data from the REDCap platform and Dr. Fabio L Tozzi for the support he provided in starting the project.

\section{Competing interests}

Dr. Marcelo Averbach is a board member for Boston Scientific, Inc. Dr. Ferrari is a medical consultant for Boston Scientific, Inc. and Olympus.
Funding

To make the project feasible, several partnerships were established with both public and private sectors. The municipal health department of Belterra provided the Municipal Hospital facilities and allowed the team of nurses and community health care agents to collaborate on the project. Fujinon Corporation provided endoscopic equipment, such as endoscopes, image processors, and screens, for every expedition. Hospital Sírio-Libanês, through its teaching and research institute, provided the software and expertise for data collection and analysis and performed histopathological tests of the sample specimens. Boston Scientific Corporation was responsible for all costs related to transport and accommodation of the team, and also provided facilities for endoscopic procedures. Moreover, the company also provided a team of two nurses who were sent to Belterra before every expedition in order to set up the working space for the rest of the team. Further, the project was supported by the Hospital Regional do Baixo Amazonas, a local secondary hospital that received patients who needed additional treatment in case of unexpected complications. The sources of funding had no role in the design, conduct, data analysis, and reporting of this study.

\section{References}

[1] Australian Institute of Health and Welfare 2016. Australia's health 2016. Australia's health series no. 15. Cat. no. AUS 199. AlHW; Canberra: 2016

[2] Condon JR, Barnes T, Armstrong BK et al. Stage at diagnosis and cancer survival for Indigenous Australians in the Northern Territory. Med J Aust 2005; 182: 277-280

[3] Hill S, Sarfati D, Blakely T et al. Survival disparities in Indigenous and non-Indigenous New Zealanders with colon cancer: the role of patient comorbidity, treatment and health service factors. J Epidemiol Community Health 2010; 64: 117-123

[4] Ward P, Javanparast S, Wilson C. Equity of colorectal cancer screening: which groups have inequitable participation and what can we do about it? Aust J Prim Health 2011; 17: 334-346

[5] Honein-Abouhaidar GN, Baxter NN, Moinedden R et al. Trends and inequities in colorectal cancer screening participation in Ontario, Canada, 2005-2011. Cancer Epidemiol 2013; 37: 946-956

[6] Kalahdooz F, Jang S, Corriveau A et al. Knowledge, attitudes, and behaviours towards cancer screening in indigenous populations: a systematic review. Lancet Oncol 2014; 15: e504-16

[7] Wardle J, Von Wagner C, Kalj-Hans L et al. Effects of evidence-based strategies to reduce the socioeconomic gradient of uptake in the English NHS bowel cancer screening program (ASCEND): four cluster randomized controlled trials. Lancet 2016; 387: 751-759

[8] Andrilla CHA, Moore TE, Man Wong K et al. Investigating the Impact of Geographic Location on Colorectal Cancer Stage at Diagnosis: A National Study of the SEER Cancer Registry. J Rural Health 2020; 36: 316-325. doi:10.1111/jrh.12392

[9] Harris PA, Taylor R, Thielke R et al. Research electronic data capture (REDCap) - a metadata-driven methodology and workflow process for providing translational research informatics support. J Biomed Inform 2009; 42: 377-381

[10] Center for Cancer Control and Information Services - NCC. Cancer statistics in Japan '13. Japan: Foundation for Promotion of Cancer Research; 2013: http://www.ncc.go.jp/en/cis/index.html

[11] Choi KS, Lee HY, Jun JK et al. Adherence to follow- up after a positive fecal occult blood test in an organized colorectal cancer screening program in Korea, 2004-2008. J Gastroenterol Hepatol 2012; 27: 1070-1077 
[12] Australian Government. Screening monograph no 6/2005. The Australian Bowel Cancer Screening Pilot Program and Beyond: final evaluation report; 2005: http://www.cancerscreening.gov.au/ internet/screening/publishing.nsf/content/9C0493AFEB3FD33CCA257D720005C9F2/\$File/final-eval.pdf

[13] Rex DK, Schoenfeld PS, Cohen J et al. Quality indicators for colonoscopy. Gastrointest Endosc 2015; 81: 31-53

[14] Rastogi A, Early DS, Gupta N et al. Randomized, controlled trial of standard definition white light, high definition white light, and narrow band imaging colonoscopy for the detection of colon polyps and prediction of polyp histology. Gastrointest Endosc 2011; 74: 593-602

[15] Buchner AM, Shahid MW, Heckman MG et al. High definition colonoscopy detects colorectal polyps at a higher rate than standard white light colonoscopy. Clin Gastroenterol Hepatol 2010; 8: $364-$ 370

[16] Subramanian V, Mannath J, Hawkey C] et al. High definition colonoscopy vs. standard video endoscopy for the detection of colonic polyps: A meta analysis. Endoscopy 2011; 43: 499-505

[17] Moriyama T, Uraoka T, Esaki M et al. Advanced technology for the improvement of adenoma and polyp detection during colonoscopy. Dig Endosc 2015; 27: 40-44

[18] Tziatzios G, Gkolfakis P, Lazaridis LD et al. High-definition colonoscopy for improving adenoma detection: a systematic review and metaanalysis of randomized controlled studies. Gastrointest Endosc 2020; 91: 1027-1036.e9. doi:10.1016/j.gie.2019.12.052

[19] Siripongpreeda B, Mahidol C, Dusitanond N et al. High prevalence of advanced colorectal neoplasia in the Thai population: a prospective screening colonoscopy of 1,404 cases. BMC Gastroenterol 2016; 16: 101

[20] Burón A, Grau J, Andreu M et al. Colorectal Cancer Early Screening Program of Barcelona, Spain: Indicators of the first round of a program with participation of community pharmacies. Med Clin Barc 2015; 145: 141-146
[21] Aniwan S, Ratanachu EkT, Pongprasobchai S et al. The optimal cut-off level of the fecal immunochemical test for colorectal cancer screening in a country with limited colonoscopy resources: a multi-center study from Thailand. Asian Pac J Cancer Prev 2017; 18: 405-412

[22] Navarro M, Nicolas A, Ferrandez A et al. Colorectal cancer population screening programs worldwide in 2016: An update. World J Gastroenterol 2017; 23: 3632-3642

[23] Liao Y, Li S, Chen C et al. Screening for colorectal cancer in Tianhe, Guangzhou: results of combining fecal immunochemical tests and risk factors for selecting patients requiring colonoscopy. Gastroenterol Rep (Oxf) 2018; 6: 132-136

[24] Lairson DR, Kim J, Byrd T et al. Cost-effectiveness of community interventions for colorectal cancer screening: low-income Hispanic population. Health Promot Pract 2018; 19: 863-872

[25] Rim JH, Youk T, Kang JG et al. Fecal occult blood test results of the national colorectal cancer screening program in South Korea (20062013). Sci Rep 2017; 7: 2804

[26] Katii M, Antoljak N, Kujundži M et al. Results of National Colorectal Cancer Screening Program in Croatia (2007-2011). World J Gastroenterol 2012; 18: 4300-4307

[27] Malila N, Palva T, Malminiemi O et al. Coverage and performance of colorectal cancer screening with the faecal occult blood test in Finland. J Med Screen 2011; 18: 18-23

[28] Rabeneck L, Tinmouth JM, Paszat LF et al. Ontario's ColonCancerCheck: results from canada's first province-wide colorectal cancer screening program. Cancer Epidemiol Biomarkers Prev 2014; 23: 508-515

[29] Llorens P. Gastric cancer mass survey in Chile. Semin Surg Oncol 1991; 7: 339-343

[30] Pisani P, Oliver WE, Parkin DM et al. Case-control study of gastric cancer screening in Venezuela. Br J Cancer 1994; 69: 1102-1105

[31] Mizoue T, Yoshimura T, Tokui $\mathrm{N}$ et al. Prospective study of screening for stomach cancer in Japan. Int J Cancer 2003; 106: 103-107 